\title{
Carbon-Ionomer Nanocomposite Wetting Properties: The Role of Ionomer Composition and Surface Roughness
}

\author{
Sonal Mazumder ${ }^{1}$, Yanfang Fan ${ }^{2}$, Chris J. Cornelius ${ }^{3, *}$ \\ ${ }^{1}$ Department of Macromolecular Science and Engineering, Virginia Polytechnic Institute and State University, Blacksburg, Virginia, USA \\ ${ }^{2}$ Department of Chemical Engineering, Georgia Tech, Atlanta, USA \\ ${ }^{3}$ Department of Chemical \& Bimolecular Engineering, University of Nebraska, Lincoln, USA
}

Email Address:

ccornelius2@unl.edu (C. J. Cornelius),fyf0627@gmail.com (Y. Fan), sonal.mazumder@gmail.com (S. Mazumder)

\section{To cite this article:}

Sonal Mazumder, Yanfang Fan, Chris J. Cornelius. Carbon-Ionomer Nanocomposite Wetting Properties: The Role of Ionomer Composition and Surface Roughness. International Journal of Materials Science and Applications. Vol. 4, No. 2, 2015, pp. 69-76.

doi: $10.11648 /$ j.ijmsa.20150402.11

\begin{abstract}
Surface hydrophobicity changes of a series of nanocomposite films were evaluated as a function of roughness and ionomer concentration. Nanocomposite surfaces were created by coating a smooth silicon wafer and micro textured surfaces based on two types of 3M micro-replicated Brightness Enhancement Films (BEF). Multiple nanocomposite surfaces were evaluated as a function of $\mathrm{Pt} / \mathrm{C}$ catalyst, a single walled carbon nanotube (SWCNT), and ionomer concentration varying between 7.5 to $27.3 \mathrm{wt} \%$ Nafion. An increase in hydrophobicity was observed for all nanocomposite surfaces as compared to bare substrates coated with ionomer. Bare substrates had observed water contact angles of $32.5^{\circ}$ on silicon, $50.8^{\circ}$ on BEF type $\mathrm{Y}$, and $91.2^{\circ}$ on BEF type P. Nanocomposites coated on BEF type P surfaces had the greatest increase in apparent contact angle starting from $101.5^{\circ}$ on a surface coated with ionomer to $140.6^{\circ}$ for an ionomer composite containing $100 \mathrm{wt} \% \mathrm{Pt} / \mathrm{C}$ followed by BEF type Y $\left(78.4^{\circ}-135.4^{\circ}\right)$ and $\mathrm{Si}\left(76.9^{\circ}-135.8^{\circ}\right)$. Nanocomposite roughness increased with increasing ionomer concentration and was inversely related to the apparent contact angle of water. Nanocomposite wetting properties were strongly dependent upon ionomer concentration and micro scale roughness contributed to wetting behavior transitioning between Wenzel and Cassie modes.
\end{abstract}

Keywords: Hydrophobicity, Contact Angle, Wetting, Wenzel and Cassie Model, Nanocomposite, Ionomer, Carbon Nanotube

\section{Introduction}

Nature's self-cleaning properties of the Lotus leaf are due impart to super hydrophobic properties created from its complex surface features and unique composition. This intriguing property has inspired the science and engineering of structured surfaces and materials in order to control their hydrophobicity. Altering the wettability of a material is achievable by changing its surface energy based on composition and surface structure or roughness [1-6]. A significant technical need exists for controlling material wetting properties in biological, electronic, mechanical, and chemical systems [7-9]. Tailored surfaces can be used to control hydrophobicity for inhibiting metal corrosion, provide surface protection from chemical and biological agents, reduce marine vehicle surface biological fouling, and optimizing fuel cell gas diffusion layer wetting.
For example, Mennini et al. [10] designed superhydrophobic materials by electrospinning polymer mats made from polystyrene and poly [tetrafluoroethylene-co(vinylidene fluoride)-co-propylene] (PTVFP). This creates a water repellant, self-cleaning, and anti-fouling surface that minimizes snow or ice accumulation on exposed structures. These structures were created using PTVFP solutions containing $200 \mathrm{~nm}$ particles of $8 \mathrm{wt} \%$ polytetrafluoroethylene (PTFE) that resulted in nominal surface contact angles of $161^{\circ}$. Atomic force microscopy imaging revealed a complex surface structure comprised of beads and fibers creating nanoscale roughness. Zhao et al. [11], created a systematic series of novel solution cast blends from poly (methylmethacrylate) (PMMA) and amphiphilic polyurethane (A-PU) that generated unique surface 
topologies of variable roughness and composition. Phase separation of these blends resulted in partitioning of PMMA and A-PU into nanodomains with a static contact angle of $160^{\circ}$. While these surfaces can have large contact angles, they are non-sliding as evidenced by the drop sticking to the surface at significant angles of tilt. When fluorinated PU (FPU) is added to the blend of PMMA and A-PU, the surface properties could be attenuated from sticking to non-sticking. This work demonstrates that surface composition, morphology, and topology can be controlled in order to tailor adhesion while still maintaining a superhydrophobic surface with a contact angle of $160^{\circ}$. Naha et al. [12] used an ethylene-air mixture to generate three zones of 'nanopearl' amorphous carbon coating on an untreated $450 \mu \mathrm{m}$ thick Si wafer. In this study, the untreated Si surface had a contact angle of $40.8^{\circ}$, which increased between $152.4^{\circ}$ and $157.1^{\circ}$ when coated with carbon. Surface hydrophobicity of polymers [13-14] and carbonaceous materials are important to electrochemical devices [12, 15-16]. In a study by Yang et al. [17], molecular dynamic studies confirmed that hydrophobic surface properties are dependent on the rootmean-square (RMS) of the surface roughness. Many present and future applications in nanotechnology will require controlling the interaction and assembly of ionomer structures for new membranes [18], enhanced mechanical structures for composites [19], enhanced actuators [20], and structured carbon-ionomer nanocomposites for polymer electrolyte membrane (PEM) fuel cells [21].

While these examples do not encompass all material efforts, it is appreciated that hydrophobicity of a surface is dependent on its chemical composition and surface structure ranging from microns to nanometers. Complex interactions are created when materials of different composition, molecular structure, and surface energy are combined in order to design multifunctional devices such as a fuel cell electrode. One challenge with real surfaces is that roughness is made up of a distribution of small-scale and non-uniform undulations that may exhibit very large contact angles for water and other high surface energy liquids.

The angle created at the interfaces of a vapor, liquid, and solid is described by a contact angle, $\theta$. A contact angle is specific to a material system and the complex interfacial interactions between these three phases. At equilibrium, the chemical potential $(\mu)$ is equivalent in these phases represented in terms of interfacial energies or surface energy $(\gamma)$. At equilibrium conditions, Equation 1 is the Young's equation relating the contact angle to the interfacial free energies at the solid-liquid $\left(\gamma_{S L}\right)$, liquid-vapor $\left(\gamma_{L V}\right)$, and solidvapor $\left(\gamma_{S V}\right)$ interfaces [22]. Fig. 1 is an idealized liquid drop resting on a flat surface forming a contact angle described by the Young's relationship.

$$
\cos \theta=\frac{\gamma_{S L}-\gamma_{S V}}{\gamma_{L V}}
$$

This relationship describes the contact angle $\theta$ created from the interfacial interactions occurring between air/vapor
(V), liquid (L), and solid (S) substrate. Hydrophilic materials are characterized by a liquid spreading on its surface and forming an angle less than or equal to $90^{\circ}$. A material is considered hydrophobic when its contact angle is between $90^{\circ}$ and $180^{\circ}$. Low surface energy materials such as PTFE produce highly hydrophobic surfaces with water contact angles as high as $120^{\circ}$. Super hydrophobic materials have contact angles greater than $150^{\circ}$ that may be created from highly rough or textured materials. Two distinct models that successfully describe the affect of increasing hydrophobicity on micro textured surfaces are the Wenzel and Cassie models.

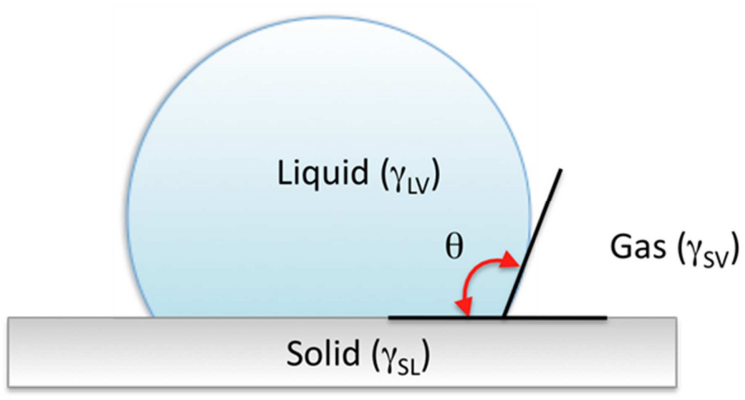

Fig. 1. Contact angle of a liquid on a surface.

The Wenzel model [23] describes the apparent contact angle $\theta^{*}$ of a surface in terms of its roughness $r$ and the intrinsic (Young's) contact angle $\theta$ (Equation 2). This model describes surfaces with moderate hydrophobicity with an intrinsic contact angle $\theta$ greater than $90^{\circ}$ but less than the critical contact angle $\theta_{c}$. The model defines the surface roughness $r$ in terms of the ratio of the projected area $A$ divided by the area of the flat surface $A_{o}\left(r=A / A_{o}\right)$. Overall, the Wenzel model utilizes roughness to describe an increase in the effective free energy of the solid/liquid interface resulting in a more hydrophobic surface.

$$
\cos \theta^{*}=r \cos \theta
$$

When air becomes trapped beneath the surface of a liquid drop, it creates a solid-air interface. The Cassie model [24] assumes an air fraction is trapped between the drop and the rough surface cavities. Because this occurs, the apparent contact angle is an average between its value in air and the solid. This angle is proportional to the Young's or intrinsic contact angle through the total surface area fraction $\varphi_{\mathrm{s}}$ in contact with the liquid based on the following relationship. The transition between the Wenzel and Cassie regimes is demarcated by a critical contact angle $\theta_{\mathrm{c}}$.

$$
\cos \theta^{*}=\varphi_{S}(1+\cos \theta)-1
$$

Hydrophobicity of carbon-ionomer nanocomposite systems is a function of surface topology and chemical composition. The focus of this work is to probe these material complexities in order to gain scientific insight associated with the surface hydrophobicity of ionomer-based fuel cell electrodes. Insight gained by this work may contribute to the design of electrodes with controlled wetting and improved mass transfer. 


\section{Experimental}

\subsection{Materials}

A series of samples were prepared using various mass concentrations of $\mathrm{Pt}$ on Vulcan $\mathrm{XC}-72 \mathrm{R}(\mathrm{Pt} / \mathrm{C})$ purchased from E-TEK Division (USA) in a $5 \mathrm{wt} \%$ ionomer solution of Nafion (DuPont) 1100 (1100 g per mole of sulfonic acid) as the matrix for thin film coatings. The weight percent concentrations of $\mathrm{Pt} / \mathrm{C}$ studied were $20 \mathrm{wt} \%, 40 \mathrm{wt} \%, 60 \mathrm{wt} \%, 80 \mathrm{wt} \%$, and 100 $\mathrm{wt} \%$. A Pt free series of samples were prepared using SWCNT purchased from Sigma Aldrich. SWCNT were created using a chemical vapor deposition process yielding 0.7-1.1 nm diameter tubes of variable length. Ionomer nanocomposite solutions were coated on three distinct substrates with varying roughness. Substrates were based on a type N (100) $380 \mu \mathrm{m}$ SSP prime silicon wafers from University Wafers (1-10 ohm$\mathrm{cm})$ and two types of $3 \mathrm{M}$ Brightness Enhancement Films $\mathrm{P}$ and $\mathrm{Y}$ (BEFP and BEFY) with varying microstructure grove distances $(\mathrm{P}-10 \mu \mathrm{m}$ and $\mathrm{Y}-300 \mu \mathrm{m})$. Water used for the measurement of contact angles was deionized to a level of 18.2 $\mathrm{M}-\mathrm{Ohms}$ and filtered with a $0.5 \mu \mathrm{m}$ filter.

\subsection{Experimental Method}

A typical coating solution was based upon $20 \mathrm{mg} \mathrm{Pt} / \mathrm{C}$ or SWCNT mixed with $170 \mathrm{mg}$ of ionomer, $140 \mathrm{mg}$ of deionized water, and $200 \mathrm{mg}$ of isopropyl alcohol. The ionomer used in this study was $5 \mathrm{wt} \%$ Nafion 1100 (1100 g ionomer per mole of sulfonic acid group) in an alcohol dispersion. All solutions were mixed with an ultra homogenizer for 4 minutes to form highly uniform and dispersed particle solutions as validated by the creation of reproducible apparent contact angles. In previous experiments, it was determined that solutions mixed with an ultrasonic homogenizer for greater than 2 minutes resulted in highly uniform solutions giving reproducible nanocomposite coatings. Uniformly coated materials were created by systematically brush coating a well-mixed composite solution onto a $10 \mathrm{~mm}$ x $10 \mathrm{~mm}$ substrate surface. Solvent free coatings were generated by evaporating the solvent at room temperature in a vacuum oven to yield coatings based on Nafion, Nafion/catalyst, or Nafion/SWCNT. Table 1 is a summary of the composition of the films used in this study.

Table 1. Mass and elemental composition of carbon-ionomer nanocomposites.

\begin{tabular}{|c|c|c|c|c|c|c|}
\hline \multirow{2}{*}{$\begin{array}{l}\text { Nanocomposite } \\
\text { Non-Ionomer } \\
\text { wt } \%\end{array}$} & \multicolumn{5}{|c|}{ Ionomer and Catalyst } & \multirow[b]{2}{*}{$\begin{array}{l}\mathrm{Pt} \\
\text { wt } \%\end{array}$} \\
\hline & $\begin{array}{l}\text { Ionomer } \\
\mathrm{wt} \%\end{array}$ & $\begin{array}{l}\mathrm{C} \\
\text { wt \% }\end{array}$ & $\begin{array}{l}\mathrm{O} \\
\text { wt } \%\end{array}$ & $\begin{array}{l}\text { F } \\
\text { wt \% }\end{array}$ & $\begin{array}{l}\mathrm{S} \\
\text { wt } \%\end{array}$ & \\
\hline $75.3(20 \% \mathrm{Pt} / \mathrm{C})$ & 24.7 & 76.5 & 2.62 & 9.57 & 0.72 & 10.8 \\
\hline $79.1(40 \% \mathrm{Pt} / \mathrm{C})$ & 20.9 & 63.7 & 2.37 & 8.79 & 0.61 & 24.6 \\
\hline $82.9(60 \% \mathrm{Pt} / \mathrm{C})$ & 17.1 & 47.4 & 1.87 & 7.97 & 0.50 & 42.2 \\
\hline $85.3(80 \% \mathrm{Pt} / \mathrm{C})$ & 14.7 & 29.4 & 1.70 & 6.98 & 0.43 & 61.5 \\
\hline $92.5(100 \% \mathrm{Pt} / \mathrm{C})$ & 7.5 & 4.6 & 1.03 & 4.96 & 0.22 & 89.4 \\
\hline
\end{tabular}

\subsection{Physical Measurements}

\subsubsection{Contact Angle}

The apparent water contact angle $\theta^{*}$ was measured with a Kruss DSA (Drop Shape Analysis) 100 surface analyzer. A water droplet volume of $7 \mu \mathrm{L}$ was the optimal volume for producing reproducible contact angle measurements with a nominal error of $+/-2.1$ degrees. All measurements were performed at room temperature and repeated three times in order to determine reproducibility.

\subsubsection{AFM and SEM}

A Nanoscope III (Veeco) AFM (atomic force microscopy) system was used to evaluate surface roughness based on changes in height and projected area for the composite nanostructures. High-resolution Schottky Field Emission SEM (scanning electron microscopy) images of the nanostructures were obtained using a LEO (Zeiss) 1550 instrument at a $5 \mathrm{kV}$ accelerating voltage in the conventional high vacuum mode.

\subsubsection{Composition}

Quantitative analysis of the chemical elements within the top few nanometers of surfaces was measured using XPS ( $\mathrm{x}$ - ray photoelectron spectroscopy) with a PHI Quantera SXM Scanning Photoelectron Spectrometer Microprobe. The mass and atomic compositions of the films were calculated using an Oxford INCA Energy E2H X-ray Energy Dispersive Spectrometer (EDS) system with a Silicon Drifted detector. A Thermo Scientific Nicolet 670 FT-IR spectrometer was used in the Attenuated Total Reflectance (ATR) with a HATR ZnSe multi-bounce crystal to measure compositional changes of a given nanocomposite surface.

\section{Results and Discussion}

Uncoated silicon wafer ( $\mathrm{SiW})$ and brightness enhancement films (BEF) based on type Y (BEFY) and type P (BEFP) had apparent water contact angles of $32.5^{\circ}, 50.8^{\circ}$, and $91.2^{\circ}$. In Fig. 2, coating surfaces with the ionomer solution resulted in an increase in the apparent water contact angles from $32.5^{\circ}$ to $76.9^{\circ}(\mathrm{SiW}), 50.8^{\circ}$ to $78.4^{\circ}$ (BEFY), and $91.2^{\circ}$ to $101.5^{\circ}$ (BEFP) for these surfaces as shown in Fig. 2. Increases in the contact angle are attributed to the more hydrophobic properties of fluorinated Nafion and substrate roughness. Fig. 3 is a summary of the observed contact angle of the composite films versus $\mathrm{wt} \%$ ionomer based upon substrate. 


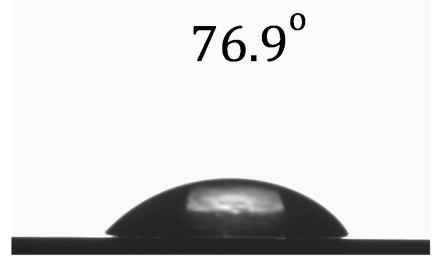

$\mathrm{Si}$

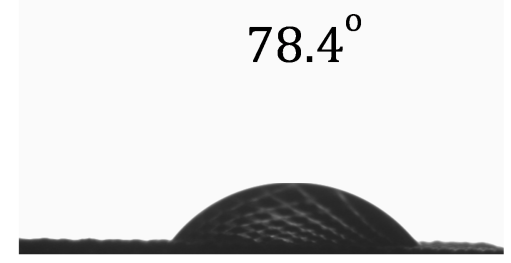

BEFP

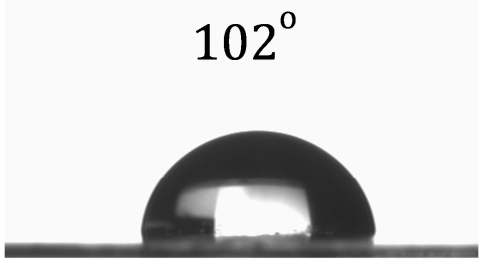

BEFY

Fig. 2. Water contact angle on various surfaces coated with ionomer as a function of roughness and surface type.

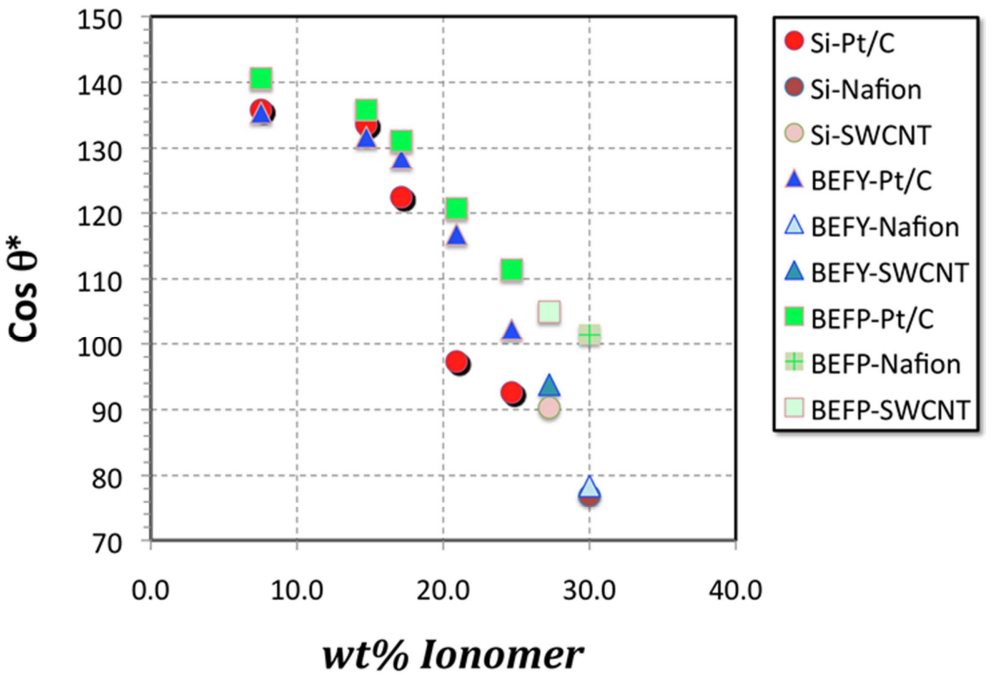

Fig. 3. Contact angle versus wt\% ionomer based on sample type.

In order to follow nanocomposite surface property transitions, the observed contact angles were modeled with the Wenzel and Cassie models. These models allow the surface complexity to be studied with respect to roughness $(r)$ and surface area fraction $\varphi_{s}$. There are significant differences in the surface topology of all nanocomposites based on the type of substrate. Differences in the apparent contact angles between these two films are attributed to smaller BEFP surface features creating less intimate contact between the water droplet and the nanocomposite surface. The Cassie model describes this air-water interface. The underlying substrate surface feature influences the nanocomposites surface and observed contact angle [13, 26-28, 31-34]. As observed with the Lotus leaf's small papillae (height 10 to 20 $\mu \mathrm{m}$ and width 10 to $15 \mu \mathrm{m})$, liquid contact on the nanocomposite surface is minimized due to feature size and liquid vapor pressure that warrants further studies. Fig. 4 is a SEM example of coated surfaces of SiW, BEFY, and BEFP with a mixture of ionomer and $20 \mathrm{wt} \% \mathrm{Pt} / \mathrm{C}$. It is apparent from this low magnification SEM image the differences in coated substrates and the persistence of feature size between SiW, BEFP, and BEFY with a coating of ionomer and catalyst or SWCNT.

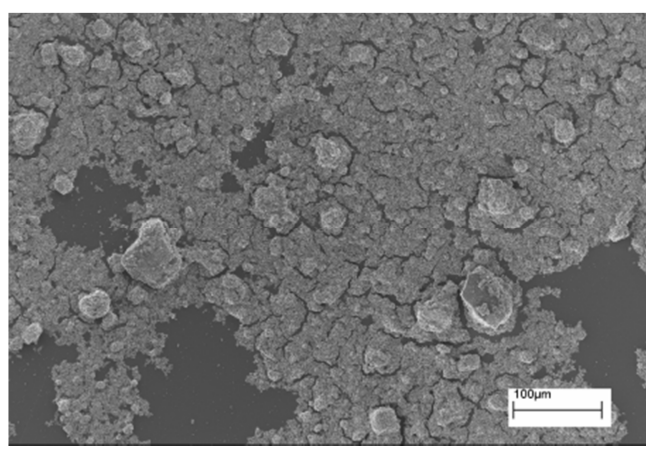

(a) $\mathrm{Si}$

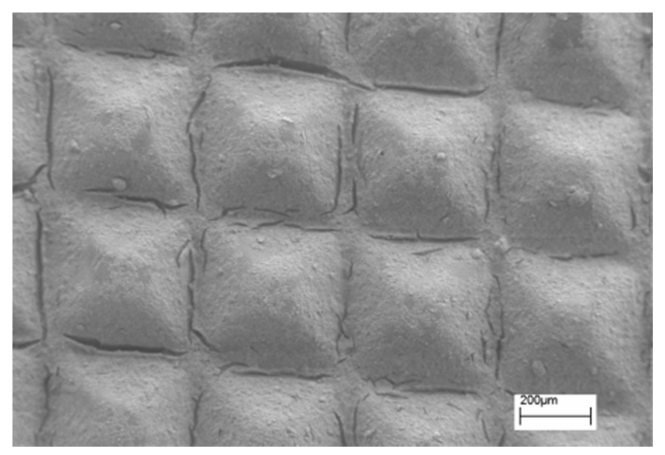

(b) BEFY 


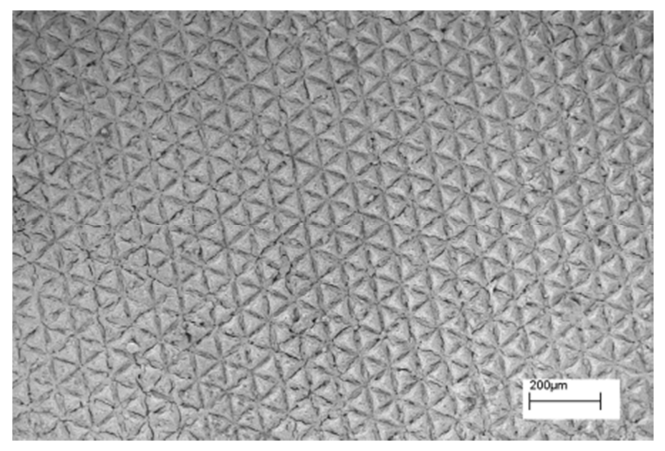

(c) BEFP

Fig. 4. SEM images of Pt/C-ionomer nanocomposite on SiW (a) $20 w t \%$ $\mathrm{Pt} / \mathrm{C}$, (b) $100 \mathrm{wt} \% \mathrm{Pt} / \mathrm{C}$, and, (c) SWCNT.

Atomic force microscopy (AFM) was used to determine the Si coated sample roughness $(r)$ and height variation (root mean square $\mathrm{RMS}, R_{q}$ ). RMS or $R_{q}$ was evaluated by measuring the height $Z_{i}$ of $N$ points within a defined area in order to calculate its geometric mean.

$$
R_{q}=\sqrt{\frac{\left(Z_{i}\right)^{2}}{N}}
$$

A typical AFM nanocomposite height image $\left(R_{q}\right)$ is shown in Fig.5a for a $20 \mathrm{wt} \% \mathrm{Pt} / \mathrm{C}$ on $\mathrm{Si}$ with a $R_{q}=13.68 \mathrm{~nm}$ and a $\mathrm{SWCNT}$ on a $\mathrm{Si}$ with a $R_{q}=17.5 \mathrm{~nm}$ (Fig. 5b). The range of $R_{q}$ for all samples varied between $13.44 \mathrm{~nm}$ to $22.9 \mathrm{~nm}$ with a surface roughness $r$ ranging from 1.48 to 3.55 , which is summarized in Table 2.

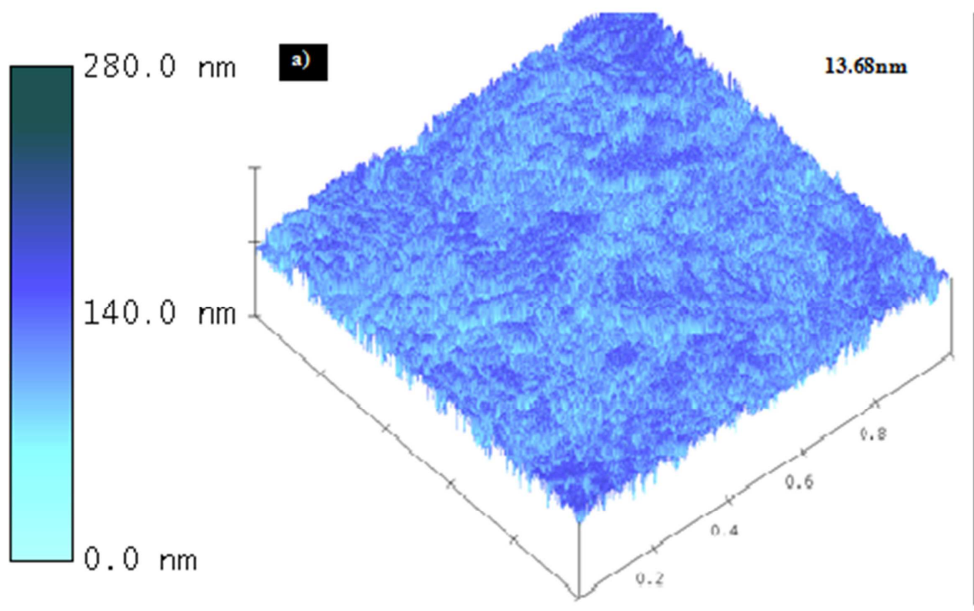

(a) $20 \mathrm{wt} \% \mathrm{Pt} / \mathrm{C}$ on $\mathrm{SiW}$

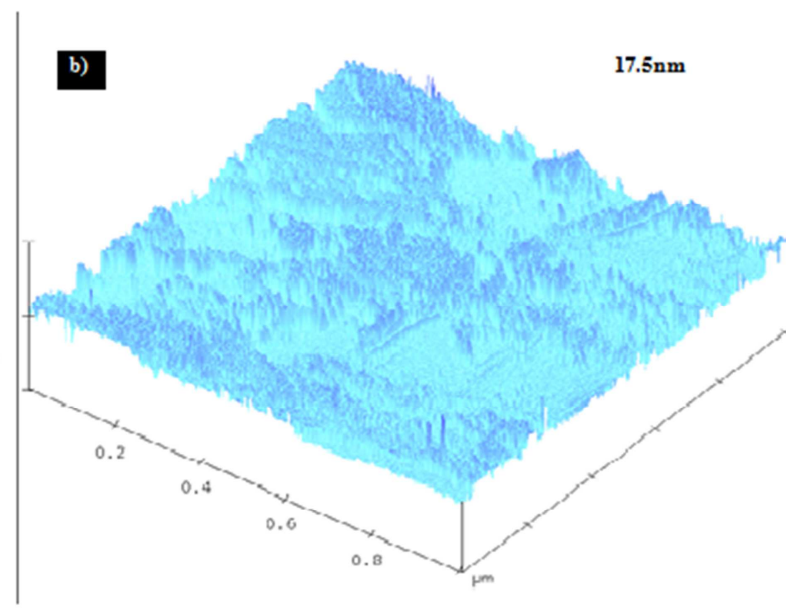

(b) SWCNT on SiW

Fig. 5. AFM images of nanocomposite ionomers on SiW (a) 20 wt\% Pt/C (b) SWCNT.

Table 2. Water contact angles, roughness, and fraction of water in contact with ionomer nanocomposite surface ( $\phi)$ on substrate SiW, BEFY, and BEFP.

\begin{tabular}{|c|c|c|c|c|c|c|c|c|}
\hline \multirow{2}{*}{ Nanocomposites } & \multicolumn{4}{|c|}{ Si substrate } & \multicolumn{2}{|c|}{ BEFY substrate } & \multicolumn{2}{|c|}{ BEFP substrate } \\
\hline & $\mathrm{R}_{\mathrm{q}} n m$ & $\mathrm{r} \mathrm{A} / \mathrm{A}_{\mathrm{o}}$ & $\theta^{*}$ & $\theta$ & $\theta^{*}$ & $\phi$ & $\theta^{*}$ & $\phi$ \\
\hline Bare substrate & 1.20 & 1.120 & 32.5 & 41.1 & 50.8 & 1.00 & 91.2 & 1.00 \\
\hline Substrate-ionomer & 3.50 & 3.551 & 76.9 & 86.3 & 78.4 & 1.00 & 101.5 & 0.75 \\
\hline SWCNT-ionomer & 22.9 & 2.205 & 90.3 & 90.1 & 93.8 & 0.94 & 105.0 & 0.74 \\
\hline $40 \mathrm{wt} \% \mathrm{Pt} / \mathrm{C}$ & 17.5 & 1.642 & 97.3 & 94.4 & 116.8 & 0.60 & 120.7 & 0.53 \\
\hline $60 \mathrm{wt} \% \mathrm{Pt} / \mathrm{C}$ & 15.3 & 1.552 & 122.4 & 110.2 & 128.4 & 0.58 & 131.1 & 0.52 \\
\hline $80 \mathrm{wt} \% \mathrm{Pt} / \mathrm{C}$ & 13.7 & 1.499 & 133.6 & 117.4 & 131.7 & 0.62 & 135.8 & 0.52 \\
\hline $100 \mathrm{wt} \% \mathrm{Pt} / \mathrm{C}$ & 13.4 & 1.482 & 135.8 & 118.9 & 135.4 & 0.56 & 140.6 & 0.44 \\
\hline
\end{tabular}

$\theta^{*}$ - apparent contact angle

Apparent contact angles of all samples coated onto $\mathrm{Si}$ substrates were adequately described by the Wenzel relationship using an inverse dependence of roughness $r$. This inverse relationship of surface roughness $r$ and apparent contact angle is counterintuitive. However, the decrease in contact angle with increasing roughness is explained in terms of the amount of ionomer in the catalyst layer. Fig. 6 is a plot of $r$ versus the observed contact angle and amount of ionomer used to make the catalyst layer. 


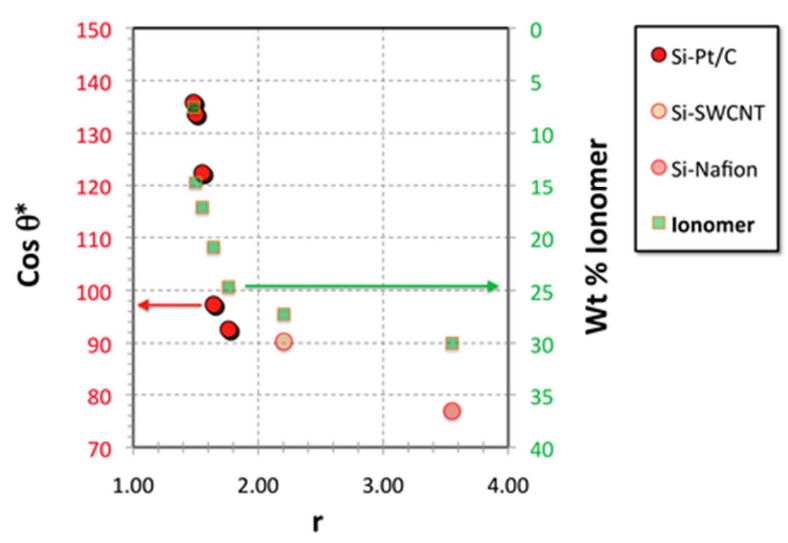

Fig. 6. Roughness $r$ versus observed $\cos \theta^{*}$ and $w t \%$ ionomer.

Based on this result, it is seen that decreases in contact angle are directly related to the amount of hydrophilic ionomer in the catalyst layer. This dominates the affect of surface roughness until a lower concentration of ionomer is

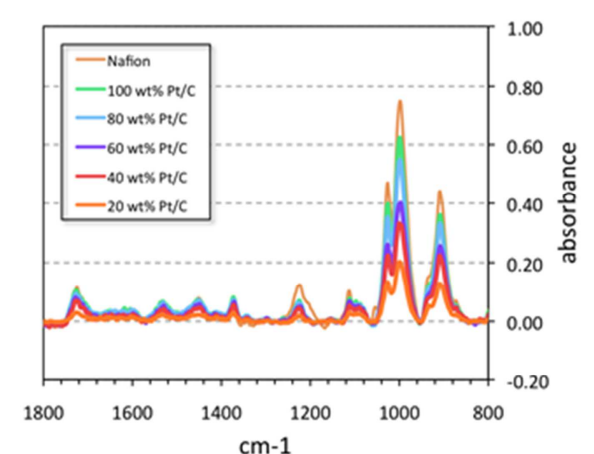

(a)

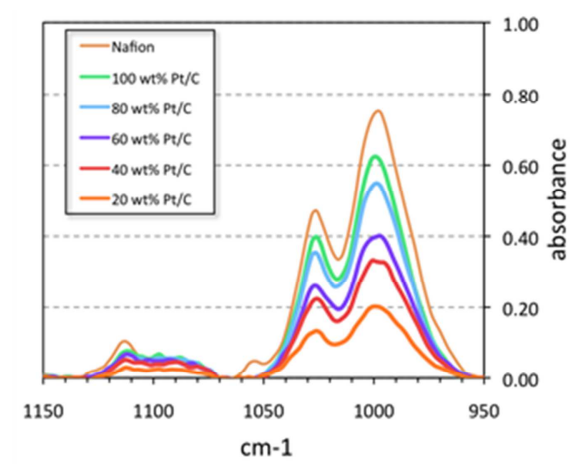

(b)

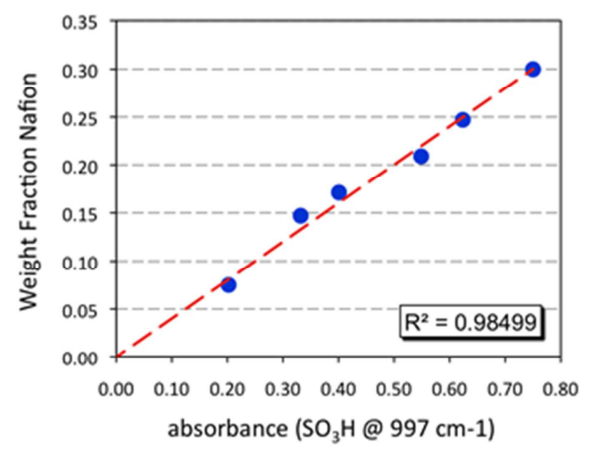

(c)

Fig. 7. (a) FTIR ATR spectra of nanocomposite films, (b) change in sulfonic acid concentration (997 cm-1) versus nanocomposite, (c) relationship between weight fraction of ionomer versus height of sulfonic acid peak (concentration).

The intrinsic contact angle $\theta$ for the nanocomposites materials was determined based on the $\mathrm{SiW}$ sample roughness $r$ obtained from AFM and the Wenzel relationship. Utilizing this relationship, the Wenzel relationship provides an excellent fit of the apparent contact angle $\theta^{*}$ versus the intrinsic contact angle $\theta$ data on all coated SiW surfaces shown in Figs 8a. Once the intrinsic contact angle was

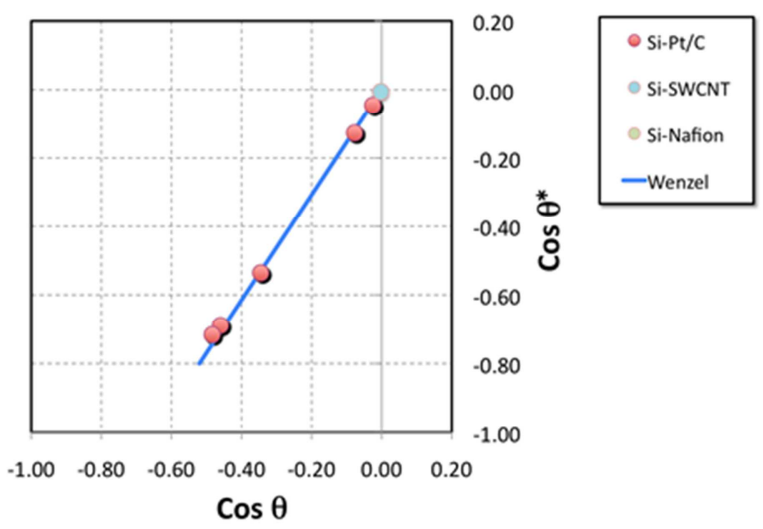

reached. Increases in observed contact angle with substrate type is due to surface feature size roughness. In this series, $\mathrm{SiW}$ is relatively smooth, BEFP has the smallest feature size, and BEFY has large-scale roughness. The apparent contact angle of a water drop on BEFP was the largest of this series and it is due to air trapped beneath surface features as described by the Cassie model and the large features of the BEFY surface followed the Wenzel model.

FTIR was done in order to measure the amount of ionomer at the surface of catalyst layer. Fig. 7a is an overview of change is surface composition based upon catalyst composite with respect to Nafion. Fig. 7b shows an increase sulfonic acid versus composition as followed by the sulfonic acid group stretch at $997 \mathrm{~cm}-1$ wave numbers. In Fig. 7c, an increase in sulfonic acid is directly related to the sulfonic acid group concentration at the surface of a film that corresponds to the weight fraction of ionomer in the composite. determined for these composites, observed contact angles transitioning between the Wenzel and Cassie regimes could be determined based upon substrate type (SiW, BEFY, BEFP) and composition of composite. Based on this result, BEFP materials were identified as transition materials because their apparent contact angles were best fit by both the Cassie and Wenzel relationships (Fig. 8b).

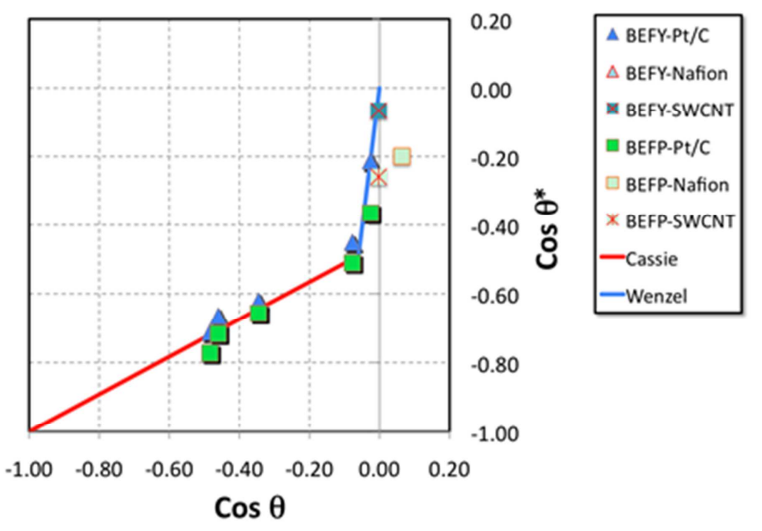

(b)

Fig. 8. Observed contact angle cos $\theta^{*}$ versus intrinsic contact angle cos $\theta$ for Cassie and Wenzel models for (a) SiW and (b) BEF films. 
This enhanced increase in contact angle for the BEFP substrate is attributed to the smaller distance between micro features. The smaller features of BEFP results in a decrease in water drop contact with the surface as compared to BEFY and Si surfaces. Consequently, more air pockets are formed beneath the water drop resulting in a larger contact angle as predicted by the Cassie relationship. While surface roughness is an important factor in an apparent contact angle, the amount of ionomer is a significant contributor to the surface properties. Fig. 6 illustrated how increasing ionomer concentration results in a decreasing apparent contact angle and a more hydrophilic surface. However, the micro roughness of a surface can significantly reduce this effect as shown for BEFY and BEFP nano-composite films at 20 and $40 \mathrm{wt} \% \mathrm{Pt} / \mathrm{C}$ and ionomer. In general, the BEFP substrate films resulted in the greatest change in contact angle as compared to BEFY and $\mathrm{Si}$ coated surfaces. At ionomer concentrations below $15 \mathrm{wt} \%$, all substrates have apparent contact angles greater than $120^{\circ}$. This result illustrates the importance of ionomer concentration and roughness on the hydrophobic and hydrophilic surface properties of an electrode. This dependence may suggest that there is a range of roughness, feature size, and ionomer surface content that is necessary for achieving high contact angles as seen with the Lotus leaf [26]. Consequently, observed changes in the apparent contact angle are attributed to the composition of the nanocomposites and its inherent roughness [29-30].

SEM (field emission scanning electron microscopy) was done in order to observe a few representative surfaces as a function of composition on SiW. Fig. 9 is a low magnification image of a Nafion nanocomposite with $20 \mathrm{wt} \%$ $\mathrm{Pt} / \mathrm{C}, 100 \mathrm{wt} \% \mathrm{Pt} / \mathrm{C}$, and a SWCNT coated on SiW. At a magnification level of 500x (1 $\mu \mathrm{m}$ marker) reveals distinct differences in surface topology based on ionomer composition. The SWCNT is relatively smooth that is attributed to a higher ionomer loading and $100 \mathrm{wt} \% \mathrm{Pt} / \mathrm{C}$ appears micro-porous and rougher than the $20 \mathrm{wt} \% \mathrm{Pt} / \mathrm{C}$ and SWCNT coating. These differences directly relate to larger contact angles observed for the $100 \mathrm{wt} \% \mathrm{Pt} / \mathrm{C}$ coatings.

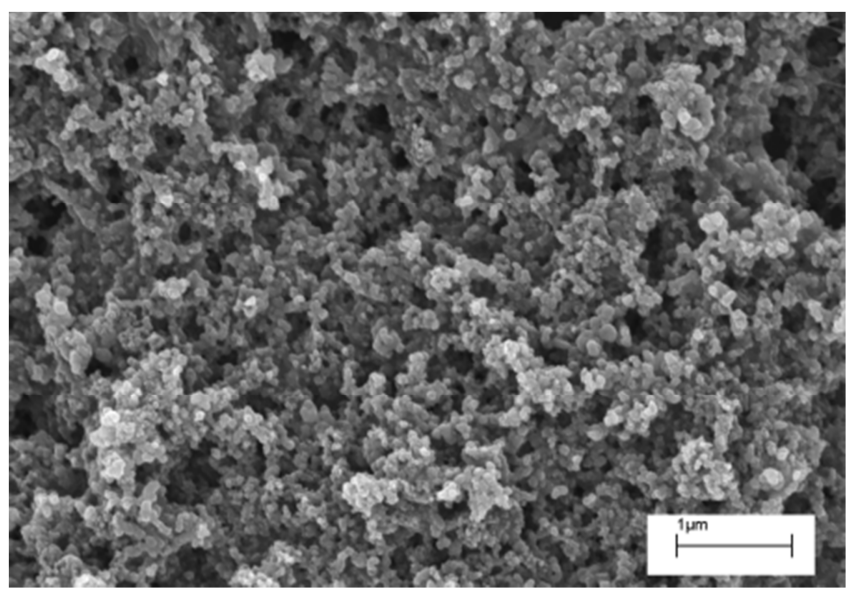

(a) $20 \mathrm{wt} \% \mathrm{Pt} / \mathrm{C}$

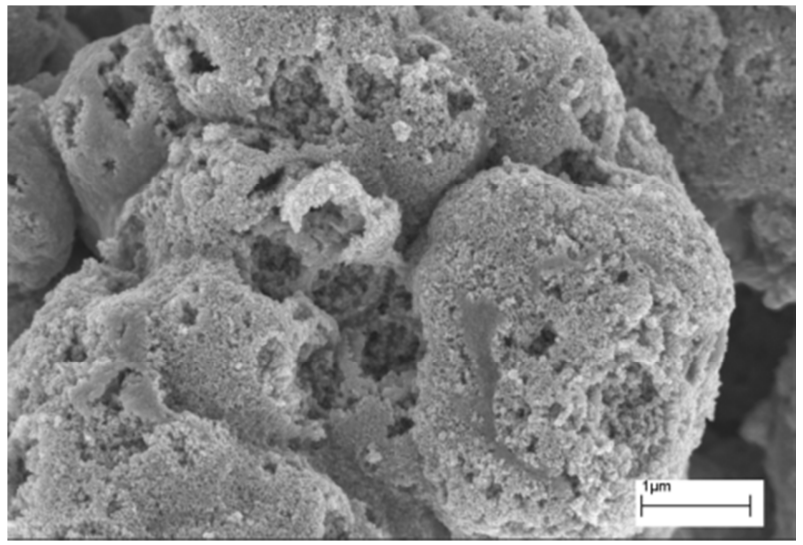

(b) $100 \mathrm{wt} \% \mathrm{Pt} / \mathrm{C}$

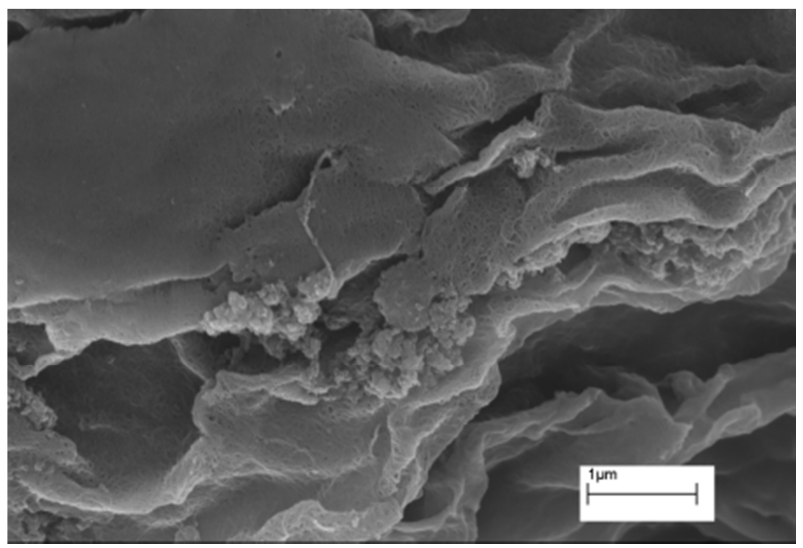

(c) SWCNT

Fig. 9. SEM images of nanocomposites on SiW of (a) $20 \mathrm{wt} \% \mathrm{Pt} / \mathrm{C}$, (b) 100 $w t \% \mathrm{Pt} / \mathrm{C}$, and (c) SWCNT.

\section{Conclusions}

The relationships between the apparent contact angle of a nanocomposite surface, its roughness, composition (ionomer, catalyst, SWCNT), and substrate pattern were studied. It was observed from this study that the underlying substrate has a profound effect on the hydrophobicity of a nanocomposite. This hydrophobicity is attributed to a decrease in the adhesive forces due to a minimization of water interfacial contact with a given surface. This property is associated with the surface roughness and the distance between surface features. Nafion ionomer content in a composite surface greater than $17 \mathrm{wt} \%$ created hydrophilic surfaces. Ionomer composites have heterogeneous surface roughness ranging from micro to nanometers, which influences its surface hydrophobicity. These small surface features increase roughness resulting in large contact angles that are characterized by Cassie and Wenzel models. The inherent surface roughness of BEF films resulted in an increase in contact angle with BEFP substrates having the greatest increase attributed to its small feature size creating roughness. The combined affects of composition and substrate leads to the variation in the contact angle observed on these surfaces. Utilizing BEF films as a model surface allowed this work to 
observe the importance and complexity of surface roughness on contact angle with water. Due to the complex heterogeneity and multiple ranges of roughness and surface features, future work is warranted to elucidate these interdependent properties.

\section{Acknowledgements}

We would like to acknowledge Mr. Steve McCartney of the Institute for Critical Technology and Applied Science (ICTAS) Nanoscale Characterization and Fabrication laboratory at Virginia Tech for help with the SEM images, Dr. Weinan Leng of the Virginia Tech Civil and Environmental Engineering for help with the AFM images, and DuPont for partial funding of this project. Finally, we would also like to thank Dr. Eugene Joseph and 3M for providing us BEF films to carry out these experiments.

\section{References}

[1] D.Y. Ryu, K. Shin, E. Drockenmuller, C.J. Hawker, T.P. Russell, Science 308 (2005) 236.

[2] X Zhang, F. Shi, X. Yu, H. Liu, Y. Fu, Z. Wang, L. Jiang, X. Li, Journal of the American Chemical Society 126 (2004). 3064.

[3] C. Zhang, H. Cai, B. Chen, W. Dong, Z. Mu, X. Zhang Chinese, Journal of Catalysis 29(1) (2008) 1.

[4] A. Marmur, Soft Matter 2 (2006) 12.

[5] J. I. Rosales-Leal, M. A. Rodríguez-Valverde, G. Mazzaglia, P.J. Ramón-Torregrosa, L. Díaz-Rodríguez, O. GarcíaMartínez, M. Vallecillo-Capilla, C. Ruiz, and M. A. CabrerizoVílchez, Colloids and Surfaces A: Physicochemical and Engineering aspects 365 (2010) 222.

[6] A. Tuteja, W. Choi, M. Ma, J. M. Mabry, S. A. Mazzella, G. C. Rutledge, G. H. McKinley and R. H. Cohen, Science 318 (2007) 1618.

[7] L. Feng, S. Li, Y. Li, H. Li, L. Zhang, J. Zhai, Y. Song, B. Liu, L. Jiang, D. Zhu Advanced Materials 14 (2002) 1857.

[8] A. R. Thiam, R. V. Farese, T. C. Walther, Nature Reviews Molecular Cell Biology, 14, (2013), 775.

[9] K. Grundke, K. Pöschel, A. Synytska, R. Frenzel, A. Drechsler, M. Nitschke, A.L. Cordeiro, P. Uhlmann, P.B. Welzel, Adv Colloid Interface Sci. (2014), doi:10.1016/j.cis.2014.10.012

[10] R. Menini,M. Farzaneh, Polymer International 57(1) (2008) 77.

[11] N. Zhao, Q. Xie, X. Kuang, S. Wang, Y. Li, X. Lu, S. Tan, J. Shen, X. Zhang, Y. Zhang, J. Xu, C.C. Han, Advanced Functional Materials 17(15) (2007) 2739.
[12] S. Naha, S. Sen, I.K. Puri, Carbon 45(8) (2007) 1702.

[13] J.D. Miller, S. Veeramasuneni, J. Drelich, M.R. Yalamanchili, G. Yamauchi, Polymer Engineering \& Science 36(14) (1996) 1849 .

[14] L. Zhang, Z. Zhou, B. Cheng, J.M. DeSimone, E.T. Samulski, Langmuir 22(20) (2006) 8576.

[15] L. Feng, Z. Yang, J. Zhai, Y. Song, B. Liu, Y. Ma, Z. Yang, L. Jiang, D. Zhu, Angewandte Chemie 115(35) (2003) 4349.

[16] C. Journet, S. Moulinet, C. Ybert, S.T. Purcell, L. Bocquet, Europhysics Letters 71(1) (2005) 104.

[17] S. Yang, Microfluidics and Nanofluidics 2(6) (2006) 501.

[18] V.M. Linkov, L.P. Bobrova, S.V. Timofeev, and R. D. Sanderson, Materials Letters 24(1-3) (1995) 147.

[19] C.D. Papaspyrides, J. Poulakis, Polymer International 27(2) (1992) 139

[20] I.A. Levitsky, P.T. Kanelos, W.B. Euler, Materials Research Society Proceedings 785 (2004) D9.1.1.

[21] M.A. Scibioha, I.-H. Oha, T.H. Lima, S.A. Honga, H. Yong, Applied Catalysis B: Environmental 77(3-4) (2008) 373.

[22] Y.T. Cheng, D.E. Rodak, Applied Physical Letters 86 (2005) 144101 .

[23] R.N. Wenzel, Industrial \& Engineering Chemistry 28(8) (1936) 988.

[24] A.B.D Cassie, S. Baxter, Transactions of the Faraday Society 40 (1944) 546.

[25] A. Lafuma, D. Quere, Nature Materials 2(7) (2003) 457.

[26] G. Zhang, S. Sun, M.I. Ionescu, H. Liu, Y. Zhong, R. Li, X. Sun, Langmuir 26(6) (2010) 4346.

[27] L.M. Nikolic, L. Radonjic, V.V. Srdic, Ceramics International 31(2) (2005) 261.

[28] M. Nosonovsky, B. Bhushan, Microsystems Technology 11(7) (2005) 535.

[29] O. Tasuku, B. Ding, Y. Sone, S. Shiratori, Nanotechnology 18 (2007) 165607.

[30] Q.Y. Tong, T.H. Lee, U. Gosele, M. Reiche, J. Ramm, E. Beck, Journal of The Electrochemical Society 144(1) (1997) 384.

[31] P. van der Wal, U. Steiner, Soft Matter 3 (2007) 426.

[32] J.T. Han, Y. Zheng, J.H. Cho, X. Xu, K. Cho The Journal of Physical Chemistry B 109(44) (2005) 20773.

[33] Y. Zhou, B. Wang, X. Song, E. Li, G. Li, S. Zhao, H. Yan, Applied Surface Science 253(5) (2006) 2690.

[34] Kah-Young Song, Han-Kyu Lee and Hee-Tak Kim Electrochemica Acta 53(2) (2007) 637. 